\title{
Retention Assessment Of Core Operations Management Topics For Business Administration Students
}

Nicole B. Koppel, Montclair State University, USA

Kimberly Killmer Hollister, Montclair State University, USA

\begin{abstract}
To meet the new AACSB International standards regarding retention assessment and adequately determine "if and what students are learning," this research presents a framework within which expected learning outcomes and specific learning are assessed. This paper presents the framework and describes how the process can be implemented with an application to retention assessment for the core operations management (OM) topics. Assessing core OM topics partially fulfills the AACSB International mandate of topical coverage and outcome assessment in the area of analytical decision making, which includes business statistics, financial analysis, and operations management. The study is of value to those who desire to better understand and implement assurance of learning or assessment in their programs.
\end{abstract}

Keywords: Retention Assessment, Assurance of Learning, Analytical Decision Making, Operations Management, Pedagogy

\section{INTRODUCTION}

$\mathscr{I}$ $\mathrm{n}$ recent years there has been a growing public dissatisfaction with the quality of college graduates (Martell and Calderon, 2005). In response, accrediting bodies, such as the Association to Advance Collegiate Schools of Business (AACSB) International, have adopted and revised their accreditation standards with a main focus on "assurance or learning (AoL)" (AASCB International, 2005). In order to achieve or re-achieve AACSB International accreditation, schools must have an assessment plan that addresses standards set forth as AoL Standards (White, 2007). Accredited schools are required to periodically assess student progress on key learning goals and to use the results to strengthen the curriculum as part of their continuing improvement efforts.

Traditionally, university programs have been evaluated based on course curriculum -- the specific material that instructors purport to teach, faculty qualifications, and admission standards. Business programs are now required to demonstrate students' accomplishment levels in terms of established learning goals. Programs are required to provide evidence, not merely intent. The new assessment standard has led faculty and administrators to search for ways to collect evidence that university students are, in fact, learning and remembering what they are taught.

This focus on retention assessment differs from the traditional grading process. Traditional grading has focused on assessing student classroom activities, effort, and performance. Retention assessment focuses on producing tangible evidence of knowledge acquisition or skill development (Mackenzie, 2004). With this increased emphasis on retention assessment and assurance of learning standards, more attention is being placed on the development and content of the curriculum through requiring specific knowledge and skills. The AACSB standards mandate topical coverage and outcome assessments in areas such as (a) communication, (b) ethics, (c) analytical decision making, (d) the use of information technology, (e) value creation chains, (f) globalization, (g) organizational leadership, and (h) appreciation for diversity and multicultural issues (Miles, Hazeldine, and Munilla 2004). 
Three key issues can be identified in the assessment process: (1) what learning needs to be assessed and to what degree; (2) how to measure and demonstrate achievement of learning goals (Zhu and McFarland, 2005) and (3) how to use those findings to strengthen the curriculum. According to Martell and Calderon (2005), in order to develop specific assessment measures, the AACSB International requires learning outcomes to be defined for each program which incorporate student mastery of knowledge and skills in these areas. These learning outcomes are used to establish specific learning goals which are the concrete observable behaviors and actions that can be measured.

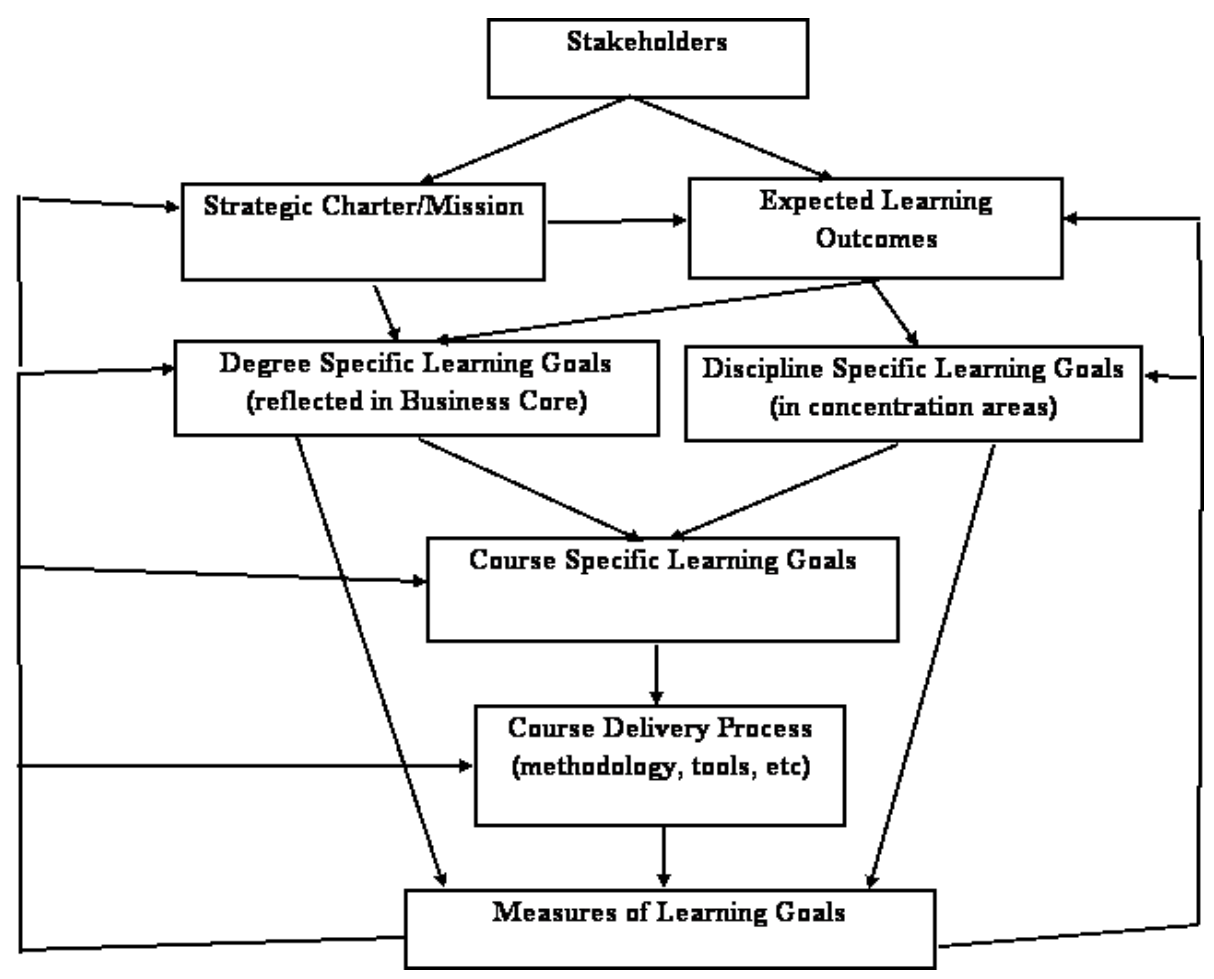

Figure 1: A Framework for Assessing Knowledge

This research paper focuses on a framework within which an undergraduate program at an AACSB International-accredited business school incorporates retention assessment in the undergraduate business administration program. The paper discusses the motivation for the assessment program, how the assessment is implemented, and at what point in the undergraduate program assessment is incorporated. The framework is illustrated with a case study in the retention assessment of core operations management topics. These include those topics on OM that all business students must understand and retain, regardless of their selected concentration (i.e. accounting, marketing, etc.).

\section{FRAMEWORK FOR ASSESSMENT}

The development of a program to assess learning goals is complex. Business programs need a stepwise process to follow to direct their efforts in the assessment arena. In Figure 1 we describe a framework (Hollister and Koppel, 2005) for the assessment of student knowledge. The remainder of this section describes each stage in the process.

The first step in the process is the identification of key Stakeholders, both internal and external. Every business school has a unique niche in the market; Stakeholder inputs drive the development of the Strategic Charter/Mission for each school. Based upon input from Stakeholders and the Strategic Charter, programs need to develop their Expected Learning Outcomes. Expected Learning Outcomes should be viewed as the broad areas in 
which programs will focus their curriculum.

The next step in the process is the development of specific learning goals for students. We break learning goals down into two categories: Degree Specific and Discipline Specific. We view the Degree Specific Learning Goals as learning goals that will be covered in either the Required General Education Courses or the Business Core Courses; courses that every business student will take regardless of concentration. Discipline Specific Learning Goals are related to the particular concentration(s) that students select within the Business Administration Degree.

Based upon Learning Goals defined for both the Degree and Concentration, Course Specific Learning Goals can be established. Course Specific Goals are translated into specific course outlines and delivered using various pedagogical techniques. Student learning occurs at the course level and learning outcomes are measured against course, discipline, and program learning goals. Evaluation of student learning should be performed; at the program and discipline level to refine curriculum and at the individual level to provide feedback that can be used to reinforce the learning of specific knowledge and skills and to assist the students in managing their learning progress.

The framework is complex because of the relationships among the three levels (Degree, Discipline, and Course); a change in the goals or techniques at any level initiates change at the other levels. For instance, the change in topics in a core course will impact both concentration and Degree Specific Learning Goals; similarly, a change in a Degree Specific Learning Goal will require changes in content of specific courses.

One aspect of assurance of learning is the realization that students may pass courses but fail to demonstrate knowledge in some subject areas. Under the new assessment guidelines, these students are required to repeat the learning process until they reach a satisfactory level of performance. Overall, the assessment process is a closedloop approach for continuous improvement to the program and assurance of learning. The emphasis is on learning.

As the AACSB International standard on AoL is relatively new, the body of literature discussing overall program assessment and discipline specific concentration assessment is rather new. Most of the literature documents methodologies that institutions are piloting to move towards meeting this new goal. Pringle and Michel (2007) and Martell (2007) provide overviews of current assessment practices. Drinka et al (2005) discus an online assessment system they develop to assist in data collection and analysis. Bycio and Allen (2004) delve into assessment through a student survey; AACSB International has stated that student outcome surveys are not sufficient to demonstrate assurance of learning. Black and Duhon (2003) explore the controversial issue of using standardized assessment tests at the undergraduate level.

As discussed above, AACSB International requires assessment in at least eight topical areas. Some of the literature focuses on assessment within these areas. As with the literature on overall program assessment, this literature is still in its infancy. Ali and Ho (2007) investigate the impact of various forms of course assessment on student performance. Fraser et al. (2005) discuss assessment in the writing aspect of communication. Hindi and Miller (2000) report results of a survey of assessment techniques in the area of accounting, Boldt (2001) presents a structural approach towards assessing accounting knowledge, Daigle et al. (2007) assesses accounting information system skills through case studies and Reffell and Whitworth (2002) examine the information technology skills of students.

\section{CASE APPLICATION - OPERATIONS MANAGEMENT}

To illustrate how the proposed framework can be used to develop an assessment program in a business school we present an application of the framework to the retention assessment of students' knowledge of the core operations management skills for all business students. Assessing core OM topics partially fulfills the AACSB International mandate of topical coverage and outcome assessment in the area of analytical decision making, which includes business statistics, financial analysis, and operations management. 


\section{EXPECTED BUSINESS OPERATIONS MANAGEMENT LEARNING OUTCOMES}

In order to achieve the Montclair State University's School of Business goal of "graduating students who are immediately effective in cutting-edge business organizations" candidates for the degree of Bachelor of Science in Business Administration must have a firm understanding of the essential concepts of operations management and be good problem solvers so that they are better prepared to assist in the decision-making process.

Another element in the Strategic Charter is the identification of "specific stakeholders as significant partners to our success as a school of business." In developing expected learning outcomes for our graduating students, we consulted with a number of our outside stakeholders as well as internal stakeholders, SBUS faculty, to develop our objectives. To this end, we consulted with textbook authors, employers, the business and professional community, and the greater academic community to identify broad objectives that each graduating student should retain.

We identify four broad expected learning outcomes relating to operations management and analytical decision making: strategy, monitoring and controlling processes, modeling, and solving business problems.

Learning Outcome 1: Students will be able to understand the role Operations Management plays in making strategic decisions.

Learning Outcome 2: Students will be able to use appropriate methods to monitor and control production and service processes.

Learning Outcome 3: Students will be able to develop appropriate mathematical models to represent real-world situations.

Learning Outcome 4: Students will be able to evaluate and solve business problems.

\section{SPECIFIC LEARNING GOALS}

The next step in the process is the identification of specific learning goals to assess; we are focusing on degree specific learning goals not learning goals associated with a specific concentration. We can also think of these as the specific competencies that will be evaluated. Specific learning goals are developed for each of the four learning outcomes identified in the previous section. For clarity, we present each of the four broad learning outcomes followed by a list with specific learning goals for that outcome.

\section{Learning Outcome 1}

Students Will Be Able To Understand The Role Operations Management Plays In Making Strategic Decisions.

- Students must be able to understand the role of a supply chain and methods to improve it.

- Students must be able to understand the importance of reducing costs throughout the supply chain

- Students must be able to understand the strategic role in the design of goods and services

- Students must be able to understand the strategic role in the selection of a location and layout of an operation

○ Students must be able to understand Project Management techniques

\section{Learning Outcome 2}

\section{Students Will Be Able To Use Appropriate Methods To Monitor And Control Production And Service Processes.}

- Students must be able to understand how to monitor quality and ensure Total Quality Management (TQM).

○ Students must be able to understand how to select, implement, and monitor appropriate forecasting techniques.

○ Students must be able to understand how to monitor and control inventory levels. 
- Students must be able to understand how to monitor and control job scheduling.

○ Students must be able to understand how to monitor and control waiting-line (queuing).

\section{Learning Outcome 3}

\section{Students will be able to develop appropriate mathematical models to represent real-world situations.}

- Students must be able to develop appropriate mathematical programming models

$\circ \quad$ Students must be able to develop decision making models

\section{Learning Outcome 4}

\section{Students will be able to evaluate and solve business problems.}

$\circ \quad$ Students must be able to determine which information is relevant to analyze business problems

$\circ \quad$ Students must be able to select an appropriate methodology for analysis and develop a model, if necessary

○ Students must be able to implement the methodology and evaluate alternatives

- Students must be able to select best alternative, implement it and monitor results

\section{MEASURING LEARNING GOALS: RETENTION ASSESSMENT TEST}

Once learning outcomes and goals are developed, the next step in the process is the development of an assessment tool to measure student knowledge. Retention assessment tests are strategically placed in the business administration curriculum to ensure that students have the requisite knowledge to take advanced courses and be immediately effective in the workplace. Prior to enrolling in the upper-level business courses, students need to demonstrate that they possess those skills that were taught in the pre-requisite courses and are assumed to be known.

The retention assessment test evaluates specific learning outcomes and goals that should be retained by students as they prepare to obtain their Business Administration degree. The exam is less comprehensive than what one might expect to see on a final exam for a course. Only major concepts are included and the expectation for passing the assessment test is commensurate with the skill level of an academically average student.

To ensure that students graduate with competency in their core operations management concepts and problem solving skills, students will be required to take the OM Retention Assessment Instrument prior to registering for their capstone business course. It is strongly recommended that students take this course during their last semester before graduation.

The OM Retention Assessment Instrument is a concepts-based exam comprised of both multiple choice and open-ended questions. Students can earn partial credit for the latter. A detailed rubric is developed for each of these questions with points awarded for the completeness of the answer and/or analysis.

\section{CLOSING THE LOOP - PROVIDING FEEDBACK}

The goal of assessment is to improve student learning. The assessment process requires us to broaden our thinking from being course-centered to focusing on the Business Administration program as a whole. Although we have worked through the process from top to bottom, we are not yet done. We must now begin the more difficult task of examining the results of the retention assessment test and closing the loop by making the required adjustments to our curriculum. In our framework, Figure 1, this is depicted as feedback from Measuring Learning Goals back up to all levels of the process from examining our strategic charter down to looking at our course delivery system. The goal is continual improvement.

The AACSB International assessment standards, requiring evidence that business students are developing the skills and knowledge base that the curriculum purports to teach, coupled with the need to evaluate and address the knowledge retention issue, have motivated the SBUS at Montclair State University to incorporate a retention 
assessment program in the undergraduate business curriculum.

Both AACSB International and the SBUS at Montclair State University recognize the ability to understand core Operations Management concepts and develop problem solving skills in a business environment as a necessity for a graduate in Business Administration. The framework for OM assessment presented in this paper describes one approach to developing and implementing a program to meeting the goal of assurance of learning.

It is expected that this assessment program will enable the SBUS at Montclair State University to truly achieve its goal of "graduating students who are immediately effective in cutting-edge business organizations."

\section{AUTHOR INFORMATION}

Nicole B. Koppel is an Associate Professor in the Department of Management \& Information Systems at Montclair State University, Upper Montclair, New Jersey. Dr. Koppel's research focus is in the broad area of Assessment in Technology and Quantitative Studies. In addition, she has published in the area of Operations Management. Her research can be found in many peer-reviewed journals including: Journal of Informatics and Education Research, Decision Sciences Journal of Innovative Education, T.H.E. Journal, and Journal of Applied Psychological Measurement. Dr. Koppel's research has been presented at numerous regional, national, and international conferences.

Kimberly Killmer Hollister is the Interim Associate Dean for the School of Business at Montclair State University; she holds a faculty position in the Department of Management \& Information Systems. Dr. Hollister earned her Ph.D. in Systems Engineering from the University of Pennsylvania. Dr. Hollister has served as the Chair of the Curriculum Committee and member of the Assessment Team. Dr. Hollister's research focuses on Educational Program Assessment and Applied Operations Management. Her recent research has appeared in /European Journal of Operational Research, Journal of Informatics and Education Research, Journal of Accountancy, Journal of Knowledge Management, and Decision Sciences Journal of Innovative Education.

\section{REFERENCES}

1. $\quad$ AACSB. (2007) Overview of Assessment. Assessment Resource Center. http://www.aacsb.edu/resource centers/assessment/overview-expectations.asp. Last Accessed April 2007.

2. Ali, Shameem and Ho, Henry W.L. (2007). Using Assessment Tasks to Shift Focus to Learning Rather than Evaluating Students, Journal of American Academy of Business, 10(2) 269.

3. Black, H. Tyrone and Duhon, David L. (2003). Evaluating and Improving Student Achievement in Business Programs: The Effective Use of Standardized Assessment Tests, Journal of Education for Business, 79(2) 90.

4. Boldt, Margaret (2001). Assessing students' accounting knowledge: A structural approach, Journal of Education for Business 76(5) 262

5. Bycio, Peter and Allen, Joyce, S. (2004). A Critical Incidents Approach to Outcomes Assessment, Journal of Education for Business, 80(2) 86.

6. Daigle, Ronald J, Hayes, David C, and Hughes II, K E (2007). Assessing Student Learning Outcomes in the Introductory Accounting Information Systems Course Using the AICPA's Core Competency Framework, Journal of Information Systems, 21(1) 149.

7. Drinka, Dennis, Voge, Kathleen, and YiMiin Yen, Minnie (2005). From Principles to Practice: Analyzing Student Learning Outcomes Assessment System, Journal of Cases on Information Technology, 7(3) 37.

8. Fraser, Linda, Harish, Katrin, Norby, Joni, Brozvoic, Kathy, Rizkallah, Teeanna, and Loewy, Dana (2005). Diagnostic and Value-added Assessment of Business Writing, Business Communications Quarterly, 68(3) 290.

9. Hindi, Nitham and Miller, Don (2000). A survey of assessment practices in accounting departments of colleges and universities, Journal of Education for Business, 75(5) 286

10. Hollister, KK and Koppel, NB (2007) Framework for Meeting AACSB International's Assurance of Learning Requirements: Application to Information Technology, Journal of Informatics Education Research, 8(3). 
11. Mackenzie, Maureen L., (2004) Business Education: Learning Outcomes, Embedded Assessments and Student Feedback, Proceedings of the Northeast Business \& Economics Association $31^{\text {st }}$ Annual Conference, New York, NY.

12. Martell, Kathryn (2007). Assessing Student Learning: Are Business Schools Making the Grade? Journal of Education for Business, 82 (4) 189.

13. Martell, Kathryn and Calderon, Thomas G., (2005) Chapter 1: Assessment In Business Schools: What It Is, Where We Are, And Where We Need To Go Now, Assessment of Student Learning in Business Schools: Best Practices Each Step of the Way.

14. Miles, Morgan P., Hazeldine, Mary F, Munilla, Linda S., (2004) The 2003 AACSB Accreditation Standards and Implications for Business Faculty: A Short Note, Journal of Education for Business, Washington: Sep/Oct, 80(1) 29.

15. Pringle, Charles and Michel, Mitri (2007). Assesment Practices in AACSB-Accredited Business Schools, Journal of Education for Business, 82 (4) 202.

16. Reffell, Pete and Whitworth, Andrew (2002). Information Fluency: Critically examining IT education, New Library World, 103(11/12) 427.

17. White, Bonnie (2007). Perspectives on Program Assessment: An Introduction, Journal of Education for Business, 82 (4) 187.

18. Zhu, Faye, X. and McFarland, Daniel (2005). Towards Assurance of Learning in Business Programs: Components and Measurements, Journal of American Academy of Business, 7(2). 
NOTES 